\title{
Low inhibitory skill leads to non-native perception and production in bilinguals' native language ${ }^{\text {is }}$
}

\author{
Shiri Lev-Ari*, Sharon Peperkamp \\ Laboratoire des Sciences Cognitives et Psycholinguistique (DEC-ENS, EHESS, CNRS), École Normale Supérieure, 29, rue d'Ulm, Paris 75005, France
}

\section{A R TICLE INFO}

\section{Article history:}

Received 4 December 2012

Received in revised form

3 June 2013

Accepted 10 June 2013

Available online 9 July 2013

\begin{abstract}
A B S T R A C T
Learning a second language influences speakers' first language, but there is great variability in the degree of influence that speakers exhibit. We show that some of this variability is due to individual differences in inhibitory skill. Particularly, we propose that poorer inhibitory skill leads to greater activation of competing items from the language not in use, and that this greater co-activation ultimately leads to greater influence of the co-activated items on one another. Specifically, we show that bilinguals with lower inhibitory skill exhibit greater influence of the second language on the first. Late English-French bilinguals residing in France produced and perceived Voice Onset Time of voiceless stops in English in a more French-like manner, the lower their inhibitory skill was. We discuss the implications of these results for the role of inhibitory skill in shaping representation in bilingual as well as monolingual language processing.
\end{abstract}

\section{Introduction}

Researchers in the field of second language learning and bilingualism as well as learners themselves usually focus on the way that a first language ( $\mathrm{L} 1$ ) can interfere or assist in the acquisition of a second language (L2). Research on the influence of L2 on L1, in contrast, is much sparser (e.g., Laufer, 2003; Pavlenko, 2003). Furthermore, bilinguals vary greatly in the degree to which their L2 influences their L1. Previous research that examined this variation among speakers has only focused on the sociolinguistic factors that govern it (Cook, 2003). We propose that a cognitive individual difference, inhibitory skill, influences the degree to which L2 influences L1 by controlling the level of co-activation of linguistic units from the competing language. In this paper, we will present supporting evidence for this hypothesis at the phonetic level.

\subsection{The interaction between the phonetic systems of bilinguals}

The acquisition of the phonetic system of L2 has been studied extensively. Most studies have focused on the way in which the phonetic categories of one's L1 influence the acquisition of those in the L2 (Flege, Bohn, \& Jang, 1997). For example, late bilinguals' production and perception of vowels in their L2 depends on the relation between the vowels in their two languages. L2 learners produce vowel contrasts in their L2 more accurately, and are better able to categorize these vowels if their L1 contains that contrast than if it does not (Flege et al., 1997).

Yet since the two linguistic systems of bilinguals are not independent of one another, successful acquisition of L2 can also influence representation and use of the L1 (Cook, 2003). According to the Speech Learning Model (Flege, 1995), bilinguals have a common phonetic space for the phones of both their languages. In the case of equivalence classification, that is, when the phones in the two languages are perceived to be similar, bilinguals will map one onto the other. In such cases, the differences between the phones in the two languages will be minimized. That is, the phones will pull one another and function as diaphones. This could lead not only to a foreign accent in speakers' production in their L2, but also to less native-like production and perception in their L1. This is particularly likely to happen if the speakers receive sufficient native input in their L2 to allow them to acquire its features, as is often the case when bilinguals live in an environment with many speakers of the L2.

Some evidence lends support to the Equivalence Model. For example, languages differ in the Voice Onset Time (VOT) of their stop consonants, which is the temporal relation between the release of a stop consonant (i.e., the burst) and the onset of voicing (Lisker \& Abramson, 1964). Some languages, such as English, are characterized by a long lag between the burst and the onset of voicing in the voiceless stops /p/, / $/$, and / $/ \mathrm{k}$, whereas

\footnotetext{
${ }^{2}$ We would like to thank Laura Cawley, Mitchell Cravens, and Anne-Caroline Fievet for their assistance. We would also like to thank Isabelle Darcy for testing the native English speakers residing in the USA. This research was funded by the Agence Nationale de la Recherche (ANR-2010-BLAN-1901, ANR-10-LABX-0087 and ANR-10-IDEX-0001-02).

* Corresponding author. Tel.: +3314432 2657 .

E-mail address: shiri.lev-ari@ens.fr (S. Lev-Ari).
} 
other languages, such as Spanish and French, are characterized by a short lag between the burst and the onset of voicing in those phonemes. Some studies of bilingual speakers of languages which differ in their VOT have found bi-directional interference in the production of voiceless stops, especially among late bilinguals (Chang, 2012; Flege, 1987; Fowler, Sramko, Ostry, Rowland, \& Hallé, 2008; Major, 1992; Sancier \& Fowler, 1997). For instance, late English-French bilinguals, even when highly proficient in their L2, produce /t/ in French with a longer VOT than monolingual French speakers. At the same time, they produce /t/in English with a shorter VOT than monolingual English speakers, reflecting an influence of their L2 on their L1 (Flege, 1987).

A closer examination of the results of these studies reveals great variation in the degree to which bilinguals differentiate the VOTs in their two languages and the degree to which the two languages influence one another. For example, both Flege (1987) and Major (1992) found that some groups or individuals hold a single phonetic category with intermediate values, while others produce voiceless stops with distinctly different VOTs in their two languages, indicating two distinct categories for the two language, even if those categories often differ from those of monolingual speakers of the two languages. As mentioned earlier, previous research that examined the variability in the influence of L2 on L1, whether at the phonetic level or at the morphosyntactic or lexical levels, mainly focused on sociolinguistic factors. L2 proficiency, age of acquisition of the L2, age of arrival to and length of residence in the $L 2$ environment, use of $L 1$, and attitudes towards the two languages have all been occasionally found to predict the influence of L2 on L1 (Cook, 2003). Here, we focus on differences in speakers' cognitive skills, and propose that inhibitory skill influences the degree to which L2 influences $\mathrm{L} 1$ by determining the degree to which bilinguals' two languages are co-activated.

\subsection{Inhibitory skill and bilingual language processing}

Bilinguals need to select the relevant language during language processing and production. The exact mechanism that is used to achieve this selection is still unclear. The Inhibitory Control model (Green, 1998) proposes that selection is achieved by exercising inhibition at the language and lemma levels with a combination of proactive and reactive control mechanisms. It further proposes that the more dominant a language is, the more inhibition is needed to inhibit it. Among the key findings in support of this model are those that come from language switching tasks. These studies show that bilinguals are slowed down on switch trials compared with same-language trials, and crucially, that switching from the less dominant language into the dominant language is slower than the other way around, presumably because of the greater inhibition needs to be overcome (Meuter \& Allport, 1999).

Others argue that selection is achieved via inhibition that is exclusively local rather than global, and directed at the specific competing lexical items (e.g., Dijkstra \& van Heuven, 2002). Among the accounts that propose that inhibition is local, some also suggest that the inhibition is reactive and automatic rather than top-down and voluntary, and therefore occurs even when it is undesired (Colzato et al, 2008; Treccani, Argyri, Sorace, \& Della Sala, 2009). Indeed, bilinguals have been shown to perform worse on tasks where inhibition is detrimental to performance, such as an attentional blink task (Colzato et al., 2008). Others still, suggest that language selection is not achieved via inhibition at all, at least not when proficiency is high (Costa \& Santesteban, 2004). We postpone the discussion of these findings to the general discussion.

Further support for the role of inhibition in bilingual language processing comes from the finding that bilinguals are better at different tasks that require inhibition, especially when the task requires focusing on one type of information while ignoring others (Bialystok \& Craik, 2010). For example, on a flanker task, where participants need to determine the direction in which a red arrow is pointing, bilinguals are less distracted than monolinguals by surrounding arrows that point in incongruent directions (Costa, Hernández, \& Sebastián-Gallés, 2008). Such advantages in cognitive control are assumed to result from bilinguals' constant practice of inhibiting the language not in use. Similar improvements in executive control with practice have been found for video game players, whose experience with attention-demanding games boosts their attentional control (Green \& Bavelier, 2003).

Recent studies have drawn a direct link between inhibition and language selection during bilingual processing (Festman, Rodriguez-Fornells, \& Munte, 2010; Gollan, Sandoval, \& Salmon, in press; Linck, Schwieter, \& Sunderman, 2011). Gollan et al. measured bilinguals' inhibitory skill using a flanker task, and then examined its predictive value for the number of language intrusion errors those bilinguals made on a speech production task. Results showed that the degree to which participants were distracted by the incongruent flankers predicted the number of cross-linguistic errors.

These lines of research, then, show that inhibition plays a role in bilingual language selection and processing. Furthermore, much evidence suggests that the irrelevant language is activated, even when the setting is monolingual. For example, when Russian-English speakers follow English instructions to move objects, such as a marker, they are more distracted by a stamp, called marka in Russian, than by a control object, even though the task is solely in English. Similarly, they are more distracted by a marker, called flomaster in Russian, than by a control object when they follow Russian instructions to move the stamp, marka, in a task that is solely in Russian (Spivey \& Marian, 1999). Activation of the irrelevant language has also been found with physiological measures and even in pairs of languages that do not share a script. For example, when Chinese-English bilinguals read or hear pairs of English words, they show a reduced N400 when the Chinese translations of the two English words share a sound compared to when they do not (Wu \& Thierry, 2010; See also Hoshino \& Kroll, 2008).

Together, the research so far suggests that inhibition plays a role in bilingual language selection, but that the irrelevant language is often simultaneously activated. In this paper, as mentioned earlier, we take up an individual differences approach. Focusing on the phonetic level, we show that individual differences in inhibitory skills influence the degree to which the two languages of a bilingual influence one another. Moreover, we propose that cross-linguistic interference during language processing can influence long-term linguistic representations. That is, whereas research so far linked inhibitory skill to momentary interference during language processing reflected in a change in response time or looks at distracting objects, we show that inhibitory skill relates to the language-appropriateness of bilinguals' ultimate production and perception. More precisely, previous studies linked inhibitory skill to the ability to process and produce language in a language-selective manner, yet speakers were always able to eventually provide a language-appropriate response. We will show that inhibitory skill is linked to whether speakers provide a language-appropriate response at all, and we show this using tasks that impose no time pressure, including ones that are quite natural (i.e., reading aloud and free conversation).

Flege's Speech Learning Model does not focus on the mechanisms at work during language processing but rather on those during language acquisition. In contrast, exemplar models focus on the processing level, and can thus potentially provide an account for how individual differences during language processing can lead to individual differences in representation. According to exemplar theory (Johnson, 1997), listeners maintain memory traces of all instances of the words they hear, together with information about the speakers and other relevant social and linguistic information. Perception and production are influenced by the activation of these stored tokens, which is determined by the similarity of the different tokens and the stored information about them to the token at hand, including the fit with its sociolinguistic information. We propose that bilinguals with lower inhibitory skill are more likely to activate each time not only the tokens from the relevant language, but also tokens from their other language. These activated tokens could pull perception and production towards them, leading to non-native perception and production. 
To test this proposal, we examined the production and perception of word-initial voiceless stops among late English-French bilinguals residing in France, and tested whether poorer inhibitory skill leads to more French-like production and perception in English, as well as whether it predicts production in French. While poorer inhibitory skill could lead to greater influence of both of bilinguals' languages over one another, differences in proficiency could obscure the effect of L1 on the L2. That is, all late bilinguals have native proficiency in their L1 before starting to acquire their L2. Therefore, deviation from native performance reflects the influence of $L 2$. In contrast, bilinguals might differ in their ability or opportunity to acquire $L 2$. Therefore, deviations from native-like performance in the L2 towards patterns of performance in the L1 could reflect either an influence of the L1 on the L2, due to low inhibitory skill, or simply incomplete acquisition. We therefore predicted inhibitory skill to predict the influence of French (L2) on English $(\mathrm{L} 1)$, but were agnostic about the relation between inhibitory skill and production in French. As we propose that inhibitory skill influences the degree to which L2 affects L1 through its role in inhibiting the language not in use during language processing, bilinguals' experience in juggling two languages might be important. The longer speakers have led bilingual lives, the longer their inhibitory skill has been used for inhibiting the language not in use, and therefore the more opportunity their languages have had to influence one another when inhibition was insufficient. We therefore also examined whether participants' length of stay in the L2 environment plays a role. ${ }^{1}$

\section{Experiment 1}

Experiment 1 focuses on production, and tests whether the inhibitory skill of late English-French bilinguals residing in France predicts their VOT in word-initial voiceless stops. We used two production tasks: sentence-reading and free conversation. Participants participated in two sessions conducted on two different days, one in English and one in French. Each session was conducted by an experimenter who was a native speaker. The French speaker pretended to not know English, and the English speaker had only limited proficiency in French. All forms, instructions and tasks were conducted in the sessions' language only.

We measured bilinguals' inhibitory skill with a Retrieval-Induced-Inhibition task (also known as retrieval-Induced Forgetting; Anderson, Bjork, \& Bjork, 1994). This task rests on evidence that shows that lexical retrieval is achieved via inhibition of competing lexical items, with items that pose greater competition being more strongly inhibited. In this task, participants memorize a list of words blocked by category. Then they are tested with a cued-recall test on a subset of the words. Crucially, participants are tested on only half of the words from some of the categories during this stage. Finally, participants perform a recognition test on all the words that they had memorized. The critical measure is the relation between participants' response time to the two types of words that had not been practiced during the cued-recall stage: inhibited words, i.e. words from categories that had been practiced, and control words, i.e. words from categories that had not been practiced. While both types of words had not been practiced, only the words from the practiced categories had been inhibited during the cued recall stage, because only they competed with the words that the participants needed to recall. Therefore, the proportional increase in response time to the inhibited vs. the control words indicates the amount of inhibition that participants exercised during cued-recall. This task therefore measures the degree to which participants rely on inhibition during language processing.

We chose this task for two reasons. Firstly, we wanted to be sure that our task taps the relevant type of inhibition, i.e., the inhibition that is used in language processing. While the type of inhibition that bilinguals use to inhibit competing languages is under debate, the nature of the RetrievalInduced Inhibition task - inhibition of competing lexical items - simulates the type of competition and inhibition that are assumed to similarly operate within and across languages (e.g., Dijkstra \& van Heuven, 2002). Secondly, we looked for a task that would be sufficiently different from our phonetic measure. This lexical memory task is very different in its procedure and its dependent measures from our phonetic production task.

We predicted that lower inhibitory skill would lead to shorter, more French-like VOTs in English (L1). We also tested whether inhibitory skill influences VOTs in French (L2).

\subsection{Method}

\subsubsection{Participants}

Thirty late English-French bilinguals participated in the study (age range: $24-78, M=48.8, S D=17.8$ ). All were native speakers of English and started learning French during adolescence or adulthood. Twenty-seven participants rated their proficiency in French, on average, higher than 6.5 on a 10-point scale on a language background questionnaire handed at the end of the experiment (see below). The three participants whose self-rated proficiency was below that threshold were excluded. All participants resided in France at the time of testing, and all had resided in a French-speaking country for at least 3 years by the time of testing (range: $4-49$, Median $=17, S D=15.4$ ). None were highly proficient in a third language although some had some knowledge of other languages.

\subsubsection{Stimuli}

2.1.2.1. Inhibitory skill task. We compiled a list of 18 English words, six for each of the categories animals (goat, horse, lion, pig, sheep, tiger), occupations (engineer, fireman, mechanic, nurse, plumber, teacher) and vegetables (broccoli, carrot, eggplant, potato, squash, zucchini). All participants learned all words in the learning stage. For the cued-recall stage, where participants practice only some of the words that they had learned, we created six counterbalanced lists. Each of these cued-recall lists contained 6 words: half of the words of two of the categories, and none from the third category. This way, each word served as a practiced word in two of the lists, as an inhibited word in two of the lists and as a control word in the remaining two lists. Each participant saw only one of the lists. Eighteen additional words from the same categories served as fillers in the final recognition test. Similarly, we compiled a list of 18 test words and 18 fillers in French for the French inhibitory skill task, using three other categories, fruit (banana, grapes, mango, pear, pineapple, strawberry), disciplines (Chemistry, Economics, Geography, History, Physics, Sociology) and hobbies (cooking, drawing, gardening, reading, swimming, yoga). Six lists for the cued-recall stage were prepared in the same manner as for the English stimuli.

\footnotetext{
${ }^{1}$ We chose this measure over the time passed since participants started learning the language, because many participants reported learning French in highschool, while adding that they neither used it nor were truly proficient in it prior to their arrival in France.
} 
2.1.2.2. Sentence reading task. We used the list of English and French sentences from Fowler et al. (2008) (See Appendix A). There were ten experimental sentences in each language, matched in terms of location of the target phone in each sentence. Each sentence had one instance of each of the target voiceless stops /ptk/; these target phones were always word-initial and followed by a vowel. In addition, each list started and ended with three filler sentences. In Fowler et al.'s study, the VOTs of the English and French monolingual control groups differed significantly. The mean VOTs of the monolingual English-speaking group were 57,74 and $76 \mathrm{~ms}$ for /p/, /t/ and / $/ \mathrm{k}$, respectively. The mean VOTs of the monolingual Frenchspeaking group for the same stops were 14,23 and $34 \mathrm{~ms}$.

2.1.2.3. Free conversation. The experimenter interviewed participants about their work (1st session) or hobbies (2nd session). The interview did not contain a set list of questions but developed according to participants' responses.

\subsubsection{Procedure}

All participants started with the inhibitory skill task, followed by the sentence reading task and finally the free conversation. The order was the same in the French and the English sessions. At the end of the second session, participants filled out a language background questionnaire, where they provided information about their age of acquisition, length of residence in French-speaking countries, patterns of language use, etc. Participants also rated their proficiency in French and English in terms of vocabulary, grammar and pronunciation on a 10-point scale.

2.1.3.1. Inhibitory skill task. The procedure was based on Veling \& van Knippenberg (2004). First, participants memorized words blocked by category. Each word appeared on the screen once, together with its category name, e.g., ANIMALS—tiger, for $5 \mathrm{~s}$, with a 1-s interval between words. Following this, participants were tested for their memory with a selective cued-recall task. During this stage, participants received a category name and the first letter of one of the words they had memorized, e.g., ANIMALS - t. Crucially, during this stage, participants were asked to recall only half of the words from two categories, and none from the third one. Each of these words was recalled three times. The presentation order within each of the three rounds of recall was random. Finally, participants received a recognition test. During this stage, participants were presented with all of the words that they had memorized initially, together with an equal number of filler words. Words were presented one by one in a random order. For each one of them, participants had to determine as quickly as possible whether it was among the words they had memorized earlier. Participants' inhibitory skill score was the ratio between their median response time to the inhibited items and their median response time to the control items. Higher inhibitory skill score therefore reflects higher inhibition.

2.1.3.2. Sentence reading task. Participants read the list of sentences at their own pace, twice. If participants were disfluent during the reading of one of the sentences, the experimenter asked them to re-read it. The sentences were recorded in a sound-attenuated room using a Microtrack II recorder set to 16 bits and a sampling rate of $44,100 \mathrm{~Hz}$ together with an AKC C1000S microphone with a frequency range of 50 to $20,000 \mathrm{~Hz}$ and sensitivity of $6 \mathrm{mV} / \mathrm{Pa}$.

2.1.3.3. Free conversation. Participants conversed with the experimenter about their work or hobbies for 10 min. We used the same microphone, recorder and location as for the sentence reading task.

\subsubsection{VOT measurement}

We measured the VOT of the 30 instances of the three target word-initial prevocalic voiceless stops in the sentence-reading task. We also extracted ten instances of each of these stops from the free conversation, when possible. The extraction of targets from the free conversation was done by searching for word-initial prevocalic voiceless stops in content words starting 3 min after the beginning of the interview, and selecting the first ten different words starting with each of these stops. If there were fewer than ten different words starting with a target stop, we selected the first repetitions of the words that had already been selected. If there were fewer than ten instances of the same word-initial voiceless stop in the examined part of the interview, even after including word repetitions, we selected the latest instances of the word-initial stop from the first three minutes of the interview.

We measured VOTs using a modified version of the algorithm used by Fowler et al. (2008). The algorithm determines the burst and voicing points according to amplitude. It first calculates the root mean square amplitude for a selected time window. It detects the maximal amplitude, and then searches for the closest prior point in time in which the amplitude reaches $40 \%$ of the amplitude of the point 8 ms prior to the maximal amplitude. This point is defined as the beginning of voicing. It then searches from the beginning of the time window for the first point in time in which the amplitude reaches at least $40 \%$ of the amplitude of the voicing point. This point is defined as the burst point. We selected these modified parameters because they detected the burst and voicing point accurately in most cases in an early sample.

In cases where the algorithm clearly failed to correctly identify the burst or stop point ( $8.8 \%$ of the data in the sentence-reading task; $20 \%$ of the data in the free conversation), VOT was measured manually. In these cases, a second naïve coder measured all the VOTs as well, and the average VOT value was taken. The median difference between coders' measurements was $3 \mathrm{~ms}$ for the sentence-reading task, and $2 \mathrm{~ms}$ for the free conversation.

\subsection{Results and discussion}

We first tested whether participants' inhibitory skill predicted their VOT in the sentence-reading task with a mixed model. ${ }^{2}$ We included Participant as a random variable with a random intercept and a slope for Phoneme, and Items as random variable with a random intercept and a slope for Language. ${ }^{3}$ The model also included the following fixed factors: Phoneme, Language, Inhibitory Skill, Length of Residence, the Phoneme $X$ Language interaction, and the Language X Inhibitory Skill X Length of Residence triple interaction including all its subsidiary lower level interactions. The results

\footnotetext{
${ }^{2}$ We used participants' performance on the English version of the inhibitory skill task. Performance on the French version of the inhibitory skill task did not predict participants' VOT

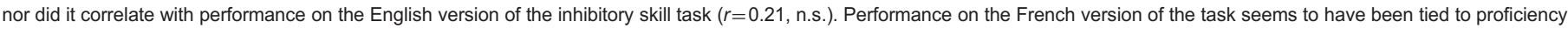
and not only to inhibitory level.

${ }^{3}$ In this and all other analyses reported in this paper, we tested for the significance of all possible slopes for the random variables by comparing a model with each slope to a model without it, using a Ratio Likelihood test (Baayen, 2008, p. 275). We included all slopes that improved the model without leading to overparameterization (Jaeger, 2008).
} 
showed a main effect of Phoneme $(\beta=-17.5, \mathrm{SD}=3.7, t=-4.8)$, such that the VOT for $/ \mathrm{p} / \mathrm{was}$ shorter than the VOTs for $/ \mathrm{k} /$ and $/ \mathrm{t} / \mathrm{s}$. This is in line with previous findings about the relation between place of articulation and VOT values (e.g., Lisker \& Abramson, 1964). The results also showed a main effect of Language $(\beta=-21.2, \mathrm{SD}=4.7, t=-4.5)$, such that VOTs in French were, on average, shorter than VOTs in English. This indicates that the speakers, in general, adjusted their VOTs in the appropriate direction according to the language they used. Furthermore, the analysis yielded an effect of Inhibitory Skill, and significant interactions between Inhibitory Skill and Length of Residence, between Inhibitory Skill and Language and between Language and Length of Residence. These were, however, qualified by a triple interaction between Language, Inhibitory Skill and Length of Residence $(\beta=-1.1, \mathrm{SD}=0.2, t=-4.6)$ (See Appendix $\mathrm{B}$ for the full table of results). ${ }^{4}$ In order to understand the nature of the triple interaction, we conducted separate analyses on the VOTs in English and in French.

A mixed model analysis of the VOTs in English (L1) revealed a main effect of Phoneme $(\beta=-17.5, \mathrm{SD}=3.6, t=-4.9)$, such that the VOTs for /p/ were shorter than those for $/ \mathrm{t} /$ and $/ \mathrm{k} /$. The analysis also revealed the predicted effect for Inhibitory Skill $(\beta=20.8, \mathrm{SD}=10.2, t=2)$. The poorer speakers' Inhibitory Skill was, the shorter, more French-like, their VOTs were. In addition, the analysis revealed an interaction between Inhibitory Skill and Length of Residence $(\beta=1.6, \mathrm{SD}=0.7, t=2.4)$, which showed that the effect of Inhibitory Skill became larger the longer participants had lived in a French-speaking environment.

A mixed model analysis of the VOTs in French (L2) revealed an effect of Phoneme $(\beta=-21.8, S D=5, t=-4.4)$, such that VOTs for /p/ were shorter than VOTs for $/ \mathrm{t} /$ and $/ \mathrm{k} /$. The analysis also revealed an effect of Length of Residence $(\beta=-0.2, \mathrm{SD}=0.1, t=-2.1)$, indicating that participants' VOTs in French were shorter the longer they had lived in a French-speaking environment. This indicates that participants' VOTs in French became more French-like with more exposure. There was neither an effect of Inhibitory Skill nor an interaction between Inhibitory Skill and Length of Residence.

We next examined whether inhibitory skill predicted participants' VOTs in the free conversation. Since the results of the sentence-reading task only revealed an effect of inhibitory skill on pronunciation in English, we only analyzed the English conversations. We ran a mixed model analysis with Participants and Word as random variables. The random variable for Word included a slope for Inhibitory Skill. The model also included Phoneme, Inhibitory Skill, Length of Residence, and an Inhibitory Skill X Length of Residence interaction as fixed effects. The results of this analysis were similar to those found in the analysis of participants' VOTs in English in the sentence-reading task. There was a main effect of Phoneme $(\beta=-10.9, \mathrm{SD}=2.1$, $t=-5.2)$, such that the VOTs of $/ \mathrm{p} /$ were shorter than those of $/ \mathrm{t} /$ and $/ \mathrm{k} /$. There was also an effect of Inhibitory Skill $(\beta=22.7, \mathrm{SD}=9, t=2.5)$, indicating that, as predicted, poorer inhibitory skill was associated with shorter, more French-like VOTs. Finally, there was an interaction between Inhibitory Skill and Length of Residence $(\beta=1.4, \mathrm{SD}=0.6, t=2.4)$, showing that the role of inhibitory skill increased the longer participants had lived in a Frenchspeaking environment.

In general, cognitive function deteriorates with age. Therefore, one might wonder whether the effect of inhibition is in fact driven by age differences. Even though age should not influence the degree of influence of a second language on the first language, except for its relation with length of residence in the second language environment, which was controlled for in the analysis, we decided to test for the correlation between inhibition and age in our sample. The analysis showed that, in fact, Age and Inhibitory Skill are not correlated in our sample $(r(25)=0.04, t<1)$, ruling out the possibility that it is age rather than inhibition that is associated with greater influence of a second language on the first language.

Together, these results support our proposal that individual differences in inhibitory skill influence the degree to which bilinguals' L2 influences their L1. Specifically, our results show that the poorer bilinguals' inhibitory skill is, the more their VOTs in their L1 shift in the direction of those in the L2. Our results further show that the role that inhibitory skill plays increases as a function of the time bilinguals have resided in their second-language environment. In other words, the more exposure bilinguals have had to their L2, and the more opportunity their L2 has had to influence their L1, the more important their level of inhibitory skill becomes in its ability to keep them immune to L2's influence. Finally, the results of this experiment show that bilinguals' production does not differ between formal and spontaneous contexts, since the results of the sentence reading task were identical to those of the free conversation.

\section{Experiment 2}

Experiment 2 was aimed at extending the findings of Experiment 1 by testing whether individual differences in inhibitory skill also influence bilinguals' representations in a perceptual task. So far, experiments that examined the influence of the phonetic system of $L 2$ on the phonetic system of the L1 focused on production tasks (Chang, 2012; Flege, 1987; Fowler et al., 2008; Major, 1992; Sancier \& Fowler, 1997). Experiment 2 tested whether bilinguals show an influence of their L2 on their L1 in a perceptual task, and whether the degree to which their perception in their L1 is influenced by the L2 is predicted by their inhibitory skill. In addition, we examined whether the degree to which the shift in participants' production and perception towards the $\mathrm{L} 2$ values were correlated.

To test this, we recruited a novel group of late English-French bilinguals residing in France and measured their inhibitory skill using the same task as in Experiment 1. We then recorded them reading the same sentences used in the sentence reading task in Experiment 1 . We did not repeat the free conversation task this time, because its results in Experiment 1 were identical to those of the sentence reading task. Next, we tested participants' perception using a phoneme categorization task, where participants heard instances of dean and teen, and for each instance, they had to decide whether it was dean or teen. VOT is one of the cues that differentiate / $/$ / and / $t /$ in English and French, but the boundary between these two phones in terms of VOT is lower in French than in English. The tokens that participants listened to only differed in their VOT, and the tokens' VOT range covered both French and English values for these words. ${ }^{5}$ Finally, participants filled out the same language background questionnaire used in Experiment 1. Since our main interest was in the influence of French (L2) on English (L1), there was only one session, conducted in English by a native English speaker, different from the one who conducted the English session in Experiment 1. We also tested native English speakers residing in the USA on the phoneme categorization task. Their performance served as a reference point, allowing us to examine how use of French has pulled bilinguals' perception away from native norms.

We predicted that participants' inhibitory skill would influence the degree to which participants' boundary between /d/ and /t/ would shift to lower values, in the direction of the French boundary. In other words, we hypothesized that poorer inhibitory skill would lead to classification of more tokens

\footnotetext{
${ }^{4}$ Examination of the scatterplots revealed that one participant had an Inhibitory Skill score that was more than 3 SDs above the mean score. We therefore re-ran the analysis without her to ensure that the effects were not driven by her. The triple interaction held, and even became slightly stronger.

${ }^{5}$ Participants also performed an AXB discrimination task at the end of the session, but we will not report its results here.
} 
as teen. Furthermore, we predicted that bilinguals whose perception shifted more in the direction of the French boundary also produce more Frenchlike VOTs in English.

\subsection{Method}

\subsubsection{Participants}

Twenty-four late English-French bilinguals participated in the study (21 females; age range: $34-75, M=54.5, \mathrm{SD}=11.8$ ). All were native speakers of English and learned French during adolescence or adulthood. All participants resided in France at the time of testing and had been residing in a French-speaking country for at least 5 years (range: $5-50$, Median $=25.5, S D=12.7$ ). Four participants who rated their proficiency in French grammar, vocabulary and pronunciation, on average, as 6.5 or lower on a 10-point scale were excluded from all analyses. None of the participants was highly proficient in a third language, although some of them had some knowledge in other languages.

In addition, twelve native speakers of English (10 females; Age: $M=21.9, S D=3.6$ ) who reside in the USA were run in a campus of a Midwestern university.

\subsubsection{Stimuli}

3.1.2.1. Inhibitory skill task. We used the same stimuli as those used in the English session of Experiment 1.

3.1.2.2. Sentence reading task. We used the same sentences from Fowler et al. (2008) that were used in the English session of Experiment 1.

3.1.2.3. Phoneme categorization task. We recorded a native speaker of American English producing the words dean and teen. We then created a token of dean from his production of teen by excising the time in between the end of the burst and the onset of voicing, and adding prevoicing from his production of dean. The natural production of teen and this edited version constituted the two poles of the dean-teen continuum; their VOTs were $89 \mathrm{~ms}$ and $-157 \mathrm{~ms}$, respectively. We then created eighteen more steps on the VOT continuum between them by gradually excising sections from the middle of the gap between the burst and the onset of voicing for the voiceless tokens, and by excising sections from the middle of the prevoicing for the voiced tokens. The steps in the predicted critical range were $3 \mathrm{~ms}$ apart; outside this range, the steps were further apart. The final VOT values for the twenty steps were: $-157,-120,-80,-40,0,10,13,16,19,22,25,28,31,35,40,50,60,70,80,89$. Two versions of the task were created such that in one version, participants categorized items as dean and teen by pressing 1 for dean and 5 for teen, and in the other version, they pressed 1 for teen and 5 for dean.

In addition, the speaker produced the words bear and pear. These productions, together with a modified token of each of the two words, were used for warm-up trials. The modified version of pear was created by excising part of the gap between the burst and the onset of voicing, and the modified version of bear was created by excising part of the prevoicing in bear.

\subsubsection{Procedure}

All participants performed the inhibitory skill task first, followed by the sentence reading task, the phoneme categorization task. At the end, they filled out the language background questionnaire.

\subsubsection{Inhibitory skill task. The procedure was identical to the procedure in Experiment 1.}

\subsubsection{Sentence reading task. The procedure was identical to the procedure in Experiment 1.}

3.1.3.3. Phoneme categorization task. After completing a brief warm-up phase with the pair bear and pear, participants completed two blocks with the dean-teen continuum. Each block started with one instance of the natural production of teen followed by random presentation of two repetitions of each of the items on steps $1-6$ and 15-20, and five repetitions of each of the items on steps 7-14. Items on steps 7-14 were repeated more times since they covered the predicted critical range whereas the other items served mostly as fillers. Due to difficulty to distinguish items within the same category, participants were unlikely to be able to tell how many items there are and how frequently each item repeats. There was a 1-s pause between participants' response and the onset of the next word.

\subsection{Results and discussion}

We first tested whether participants' inhibitory skill predicted their categorization of words as dean. One participant was excluded from all analyses because her inhibitory skill score was more than 3 SDs higher than the average inhibitory skill score.

Since all participants categorized items $1-7$ as dean and items $15-20$ as teen $100 \%$ of the time, our analysis focused on responses to items $8-14$ (VOT of 16-35 ms; see Fig. 1). We carried out a mixed model analysis with Participants as a random variable, and Item, Inhibitory Skill, Length of Residence, Hand, and the Hand X Item, as well as Item X Inhibitory Skill X Length of Residence interactions and all their lower level interactions as fixed factors. The factor Hand is an artifact of the task and indicates whether participants used their dominant or subordinate hand to categorize tokens as dean. Results revealed an effect of Item $(\beta=-1.6, \mathrm{SD}=0.1, z=-12.7, p<0.001)$, such that items with higher VOTs were less likely to be categorized as dean. Since VOT is one of the factors differentiating dean from teen, with higher VOTs being associated with teen, this is predicted, and shows that the participants used VOT as a cue for classification. Results also revealed an effect of Hand $(\beta=-5.1, S D=2.2, z=-2.4, p<0.02)$, showing that participants were more likely to categorize words as dean if the response key for dean was associated with their dominant rather than subordinate hand. There was also a marginal interaction between Hand and Item $(\beta=0.3, \mathrm{SD}=0.2, z=1.8, p<0.07)$, such that the role of Hand became smaller with higher VOTs. Importantly, the results revealed an effect of Inhibitory Skill $(\beta=10.4, \mathrm{SD}=4.4, z=2.4, p<0.02)$, such that the likelihood of categorizing an item as dean decreased with lower Inhibitory Skill. Given that /d/ has a shorter VOT than /t/, and that the boundary between them is located at a lower value of VOT in French than in English, this means that lower Inhibitory Skill coincides with a shift towards a French-like boundary, with more tokens being categorized as teen. Results also revealed an interaction between Inhibitory Skill and Length of 


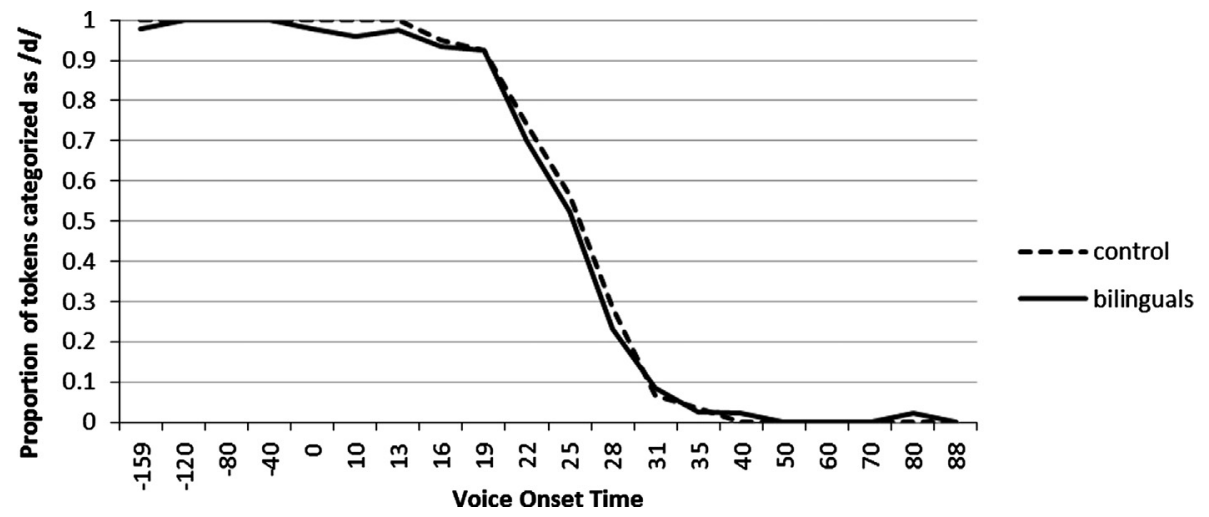

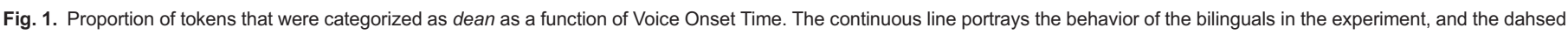
line portrays the behavior of the control participants.

Residence $(\beta=0.7, \mathrm{SD}=0.3, z=2.6, p<0.01)$, such that the role of Inhibitory Skill increased the longer participants had resided in a French-speaking environment. Yet the results also revealed an interaction of Inhibitory Skill and Item and a triple interaction of Inhibitory Skill, Item and Length of Residence $(\beta=-0.1, \mathrm{SD}=0.02, z=-2.9, p<0.01$; see Appendix $\mathrm{C}$ for the full table of results).

In order to better understand the nature of the triple interaction, we examined separately items which monolingual speakers of English categorized as dean and those they categorized as teen. Since the influence of French should be to lead participants with relatively low inhibitory skill to categorize as teen items which monolingual English speakers categorize as dean, this influence should be restricted to items that monolinguals categorize as dean. We therefore examined the responses of the native English speakers who live in the USA to determine the boundary between dean and teen. An examination of their data showed that item $11(25 \mathrm{~ms})$ is at the boundary. This item was categorized as dean roughly half of the time $(52 \%)$. We therefore ran separate analyses on items 8-10 (16-22 ms) and on items 11-14 (25-35 ms).

An analysis of participants' categorization of items $8-10$ revealed an effect of Hand $(\beta=-1.9, \mathrm{SD}=0.6, z=-3, p<0.01)$, such that participants were more likely to categorize an item as dean if they were using their dominant hand for this categorization. Crucially, the results also revealed an effect of Inhibitory Skill $(\beta=2.8, S D=1.3, z=2.2, p<0.04)$, such that more items were categorized as teen the lower participants' Inhibitory Skill was, in line with a shift towards the French boundary. The interaction between Inhibitory Skill and Length of Residence did not reach significance $(z<1, p>0.1)$ even though the coefficient remained in the same direction. An analysis of responses to items $11-15$ did not reveal any effects or interactions (all z's $<1.5$, all p's $>0.1)^{6}$

As in Experiment 1, we wanted to verify that the effect of inhibition on the influence of a second language on the first language is not driven by age. We therefore tested for the correlation between the two. Results indicated that Age and Inhibitory Skill were not correlated in our sample $(r(18)=0.12$, $t<1$ ), indicating that the effect of inhibition is not driven by age differences.

The results of the perception task, then, support the hypothesis that inhibitory skill influences the degree to which bilinguals' perception in their L1 shifts in the direction of the perceptual categories of their L2. We next examined whether participants' inhibitory skill influenced their production, and whether there was a relation between their performance in perception and that in production.

A mixed model analysis with Subjects and Items as random variables and Phoneme, Inhibitory Skill and Length of Residence as well as the interaction of Inhibitory Skill and Length of Residence as fixed effects only revealed an effect of phoneme $(\beta=-20.1, \mathrm{SD}=4.3, t=-4.7)$, indicating that the VOTs of $/ \mathrm{p} /$ were shorter than those of $/ \mathrm{t} /$ and $/ \mathrm{k} /$. Thus, we did not replicate the finding in Experiment 1 that inhibitory skill is associated with bilinguals' VOT in their native language.

There are two potential reasons for our failure to replicate the production results of Experiment 1 . One possibility is the difference in the range of participants' Inhibitory Skill between our samples. Indeed, participants' range of Inhibitory Skill in Experiment 2 consists of only a subset of that of the participants in Experiment 1 (See Appendix C). In fact, the two ranges marginally differ $(t(1,43)=1.8, p<0.07)$. It could be that the limited range in Experiment 2 prevented us from finding an effect of inhibitory Skill on production.

A second likely explanation lies with the difference in experimenter. While both studies were conducted by native speakers of American English, the experimenter in Experiment 2 had been living in France longer than the experimenter in Experiment 1, her proficiency in French was much higher than his, and her use of French in daily life was extensive. Informal evaluation of her production and her perception on similar tasks to those that participants performed showed that, like our participants, her production and perception showed influence of French. For example, her boundary between /d/ and /t/ occurred at $22.5 \mathrm{~ms}$, and her boundary between $/ \mathrm{g} /$ and $/ \mathrm{k} /$ occurred at $-7.5 \mathrm{~ms}$. For comparison, another group of monolingual English speakers, who performed the same version of the task, exhibited a /d///t/ boundary at $29.5 \mathrm{~ms}$, and a/g/-//k/ boundary at $13.7 \mathrm{~ms}$. We hypothesize that the interaction with her destabilized participants' production. Additionally, some participants might have tried to accommodate to her independently of their inhibitory skill and habitual production of stops, thus adding noise, and masking the effect of inhibitory skill. Perception performance might have been more immune to this influence either because, unlike the production task, it was done in isolation with the experimenter in a different room and not in an interactive setting, or because of differences in the degree to which perception and production are malleable and sensitive to interference from a conversational partner.

We next examined the relation between participants' production and perception. Participants' production was only moderately related with their perception. That is, the point at which a participant no longer categorizes all tokens of an item as dean predicted participants' VOTs in production $(\beta=1, \mathrm{SD}=0.5, t=2.1)$, but other perceptual measures, such as the boundary between $/ \mathrm{d} /$ and $/ \mathrm{t} / \mathrm{-}$ which is indicated by equal likelihood of categorizing an item as dean and as teen - or the first item that is categorized as teen $100 \%$ of the time, did not. Therefore, the relation between

\footnotetext{
${ }^{6}$ The background questionnaire we administered asked participants whether they suffer from any hearing impairments. Three of the included participants reported positively. Their

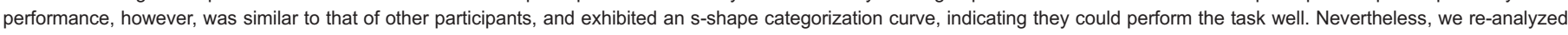

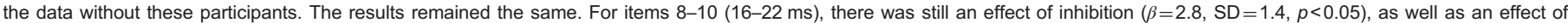
dominant hand $(\beta=-1.8, \mathrm{SD}=0.7, p<0.02)$. For items $11-14(25-35 \mathrm{~ms})$, there was still no effect of inhibition $(\beta=0.6, \mathrm{SD}=1.2, p>0.6)$.
} 
production and the first point at which an item is no longer consistently categorized as dean might be spurious. In general, production often does not correlate or correlates only moderately with perception. While most of the evidence concerns perception and production in L2 (see Peperkamp \& Bouchon, 2011, and references cited therein), Evans and Iverson (2007) examined whether students from northern England who moved to a different region changed their production and perception of their native English dialect as a result of the move. While overall accentedness correlated with speech in noise recognition and with F1 perception on two of the four items, it did not correlate with F2 or duration perception on any of the items, nor did changes in production correlate with any measure of perception on any of the items. In general, the speakers attenuated their northener accent over time, without exhibiting any change in their perception. Sumner and Samuel (2009) examined the perception of covert dialect speakers, that is, speakers with extensive exposure to a regional dialect but who do not produce the regional dialect in their speech. They found that the performance of such speakers depends on the task. Specifically, they perform like overt dialect speakers on tasks that test immediate priming, but like non-dialect speakers on tasks that test long-term priming.

Additionally, there are likely to be differences in the degree to which production and perception are malleable, and in the degree to which they are sensitive to interference from a conversational partner. The production data might have been more contaminated by the speech of the experimenter, reducing its relation to perception.

Regardless of the reason for the null results in the production task, Experiment 2 extends previous literature and Experiment 1 by showing that L2 can influence perception in L1, and that the degree to which L2 exerts such an influence depends on speakers' inhibitory skill.

\section{General discussion}

Much research in bilingualism has focused on whether bilinguals have joint or separate representations of their two languages and whether lexical access is language selective (e.g., Dijkstra \& van Heuven, 2002; Green, 1998). We propose that, among other things, individual differences in inhibitory skill influence the degree to which access is selective, and that these individual differences in ability to inhibit the language not in use have consequences for language perception and production. Specifically, we propose that poorer inhibitory skill results in greater co-activation of the competing linguistic units, and that this co-activation can ultimately influence representation.

Experiment 1 shows that individual differences in inhibitory skill predict the degree to which the production in the L1 of late bilinguals living in their L2 environment shifts in the direction of the values of their L2. The lower inhibitory skill late English-French speakers had, the more French-like their pronunciation of word-initial voiceless stops in English was, even though the task was solely in English and the experimenter was a native speaker of English. The results of Experiment 1 further show that the level of inhibitory skill becomes more important with more exposure to the L2. This is presumably because the longer speakers have had to use their inhibitory skill to control their languages, the more opportunities the L2 has had to influence speakers' L1 when inhibition was insufficient, and thus the more important inhibitory skill has become in immunizing speakers to the L2's influence. Experiment 2, despite failing to replicate the production results because of methodological issues, extended the findings by showing that individual differences in inhibitory skill can similarly predict native language perception of late bilinguals living in their L2 environment. The poorer inhibitory skill late English-French speakers had, the more likely they were to perceive as teen tokens that monolingual English speakers perceive as dean, indicating that their boundary between /d/ and /t/ shifted to lower, more French-like VOT values.

We proposed that these effects on bilinguals' phonetic system are due to the role of inhibitory skill in controlling co-activation of competing phones from bilinguals' two languages. This co-activation influences which exemplars are perceived as better or more prototypical, and thus guides and influences language production and perception. In other words, bilinguals with relatively high inhibitory skill are more likely to activate each time only the language-relevant exemplars, and thus are better able to maintain different and language-appropriate representations for their phones in their two languages. In contrast, bilinguals with poorer inhibitory skill are more likely to activate more exemplars from the irrelevant language, which eventually influences the representations that guide their production and perception. These results thus provide further evidence for the joint phonetic space that bilinguals have for their two languages. At the same time, they show that whether or not the phonemes of the two languages are treated as diaphones depends on speakers' inhibitory skill.

It is interesting to note that some findings by Costa and Santesteban (2004) suggest that proficient bilinguals can select the relevant language without exercising inhibition. In their studies, Costa and Santesteban showed that while language learners with low proficiency show asymmetrical costs in languageswitching tasks, which reflect the asymmetrical inhibition that had been exercised, leaners who achieve high proficiency in L2 no longer exhibit asymmetrical costs even when switching between their native language and a third language they do not know well. Costa and Santesteban interpreted this finding as indicating that with high proficiency, bilinguals learn how to control their languages in a manner that does not rely on inhibition, and later use this alternative method for language control when learning additional languages. The participants in our study were all highly proficient bilinguals. Still, their inhibitory skill score predicted the degree to which they exhibited an influence of their L2 on their L1. One hypothesis to account for this discrepancy is that whether or not highproficiency bilinguals rely on inhibition for language selection depends on multiple factors, such as the similarity of their languages, the contexts in which the languages are used or had been learned and so forth. Another possibility is that our measure of inhibitory skill indicates the degree to which inhibition is exercised rather than how good inhibition is. In other words, it could be that low inhibitory skill score reflects lower use of inhibition rather than reduced ability to use it. In that case, our results suggest that the tendency of proficient bilinguals to reduce their reliance on inhibition for language control leads to increased influence of the L2 on the L1. At the same time, it is important to note that the inhibitory skill measure we used does not examine inhibition during language selection but rather inhibition during L1 processing, and it is unclear whether highly proficient bilinguals who learn how to achieve language control without relying on inhibition also avoid using inhibition during lexical selection in their L1.

Our participants lived in the L2 environment, and used both of their languages on a daily basis. Importantly, all our participants reported their L1 to still be their dominant language. Therefore, the influence that the L2 exercised over their L1 was not due to a shift in language dominance. Most previous studies that found an influence of L2 on L1 at the phonetic level included participants who likewise lived in an L 2 environment (Chang, 2012; Flege, 1987; Major, 1992; Sancier \& Fowler, 1997), Yet one study examined bilinguals who had been raised in a bilingual environment in which they were still living at the time of testing. These early bilinguals also showed an effect of L2 on L1 (Fowler et al., 2008). Furthermore, a study on the influence of L2 on L1 at the semantic-conceptual level found such cross-linguistic influence even though half of the participants resided in their L1 environment (Athanasopoulos \& Kasai, 2008). Additionally, several studies that examined cross-linguistic interference during language processing found an influence of L2 on L1 even among advanced L2 learners who reside in their L1 environment (e.g., Van Hell \& Dijkstra, 2002). It therefore seems plausible that effects of L2 on L1 at the phonetic level can also be evident in $\mathrm{L} 2$ learners residing in their $\mathrm{L} 1$ environment, assuming they receive sufficient native $\mathrm{L} 2$ input. 
While the tasks we utilized focused on influence at the phonetic level, individual differences in inhibitory skill could influence performance and representations at other linguistic levels as well. For example, some evidence shows that individual differences in executive function influence representations at the conceptual-semantic level (Lev-Ari, Peperkamp, \& Keysar, 2012 ). In a picture similarity task, bilinguals with higher working memory performed differently in their two languages; their similarity rating was influenced selectively by the common way to refer to the depicted objects in the language in which they received instructions. In contrast, bilinguals with lower working memory were influenced by the common way to refer to the depicted objects in both their languages, regardless of the language in which they received instructions. Thus, executive function, by controlling the degree to which items from the competing language have been activated over years of bilingual experience, influenced the associations that those items had. Translation equivalents often differ in subtleties of meaning and use. Therefore, failure to inhibit a competing translation equivalent leads to its activation in inappropriate contexts. This could eventually lead to the formation of associations between the inappropriate contexts and the item in question, and thereby influence its meaning and use. A similar influence could occur at other linguistic levels as well.

Furthermore, inhibition is an integral part of language processing in general, even among monolinguals. For example, when homonyms are processed, their dominant meaning is initially activated, even in contexts when it is not relevant, and is only later inhibited (e.g., Gernsbacher, Varner, \& Faust, 1990; Giora, 2003). Therefore, individual differences in inhibitory skill could influence the degree to which the two meanings are co-activated, and thus influence their perceived similarity. Some evidence suggests that this is indeed the case (Lev-Ari et al., 2012).

To conclude, the present experiments show that theories of language processing and representation should integrate individual differences in cognitive skills. They show that there is variability in the way that people represent linguistic units and that individual differences during language processing could explain them. Such variability in language representation can have implications for theories of linguistic representation and communication in general, as it can influence communicative success, and interpretation of literary language.

\section{Appendix A. Stimuli for the sentence reading task}

These sentences were originally used by:

Fowler, C.A., Sramko, V., Ostry, D.J., Rowland, S.A. \& Hallé, P. (2008). Cross language phonetic influences on the speech of French-English bilinguals. Journal of Phonetics, 36, 649-663.

Sentences 1-3 and 14-16 are filler sentences. The target phonemes are indicated in bold (they were written in plain text for the participants).

\section{A.1. English sentences}

1. Ben bought some flowers and put them on his dining room table.

2. Seven hungry children crowded around the buffet.

3. Miranda's job was boring, and she fell asleep at her desk.

4. At the store, Kate purchased a tape recorder and a new stereo.

5. As recently as two days ago, Lucy parked her car at the grocery store, and she forgot where she left it.

6. Fred wore a heavy parka and comfortable boots on the hike up Tabletop Mountain.

7. Driving along the turnpike, Kayla listened to polkas on the radio.

8. On his perch, the tiny bird called to his mate.

9. Braving the raging surf, Peter caught a towering wave and rode his surfboard to shore.

10. Over the holiday weekend, Marvin performed his magic tricks, keeping his brother Tommy amazed and amused.

11. Bonnie covered the stewed tomatoes and turned down the burner before starting to work on some pies for dessert.

12. Every time he sneaked down the stairs hoping to get himself a snack, Paul's wife caught him and handed him a carrot or a piece of celery.

13. Depressed that the dentist had found three cavities, Tim pestered his mother to buy him some chocolate candy.

14. While waiting for her car to be fixed, Linda watched TV.

15. Looking through the telescope, the students saw Venus.

16. Colin browsed in the book store while his sister shopped for a new briefcase.

\section{A.2. French sentences}

1. II a acheté des roses et les a mises dans un très beau vase.

2. Les enfants,affamés, prenaient d'assaut le buffet.

3. Son travail est si ennuyeux qu'elle s'est endormie sur son bureau.

4. Avant-hier, Catherine a eu peur des termites qui ont dévoré les poutres.

5. C'est tout ce que l'ami Paul avait caché dans ses affaires: une vieille boîte d'allumettes.

6. Dans la doublure de sa parka, il cachait au moins une bonne centaine de timbres de Bosnie-Herzégovine.

7. A l'autre bout du terrain, Karine dansait la polka avec Ronaldo.

8. J'ai eu peur: ce taxi me collait de trop près.

9. Lorsque j'ai visité Pékin, un cortège de taoïstes défilait devant l'ancienne cité impériale.

10. C'est sûrement au cours de la soirée qu'il a perdu le précieux kimono de son frère Tobie, un cadeau de leur grand-mère.

11. Dans le couvent ce sont les tomates qui semblent être l'objet de tous les soins; les nonnes s'inquiètent de leur pâleur cette année.

12. Le grand tapis iranien aux motifs si sophistiqués, posé là en attendant, donnait à Caroline un peu de répit.

13. Comme le dentiste lui avait trouvé des caries, Tim pestait contre sa sœur qui lui donnait trop de bonbons.

14. En attendant que le café soit prêt, Laure lisait le journal.

15. Grâce au nouveau télescope, on peut voir Vénus.

16. Nicolas fouinait dans les rayons de la librairie pour le plaisir. 
Appendix B. Tables of results of Experiment 1

Table of results for VOTs in the sentence-reading task:

\begin{tabular}{|c|c|c|c|}
\hline Variable & Estimate $(\beta)$ & SD & $t$ \\
\hline (Intercept) & 70.21128 & 2.89116 & 24.285 \\
\hline Phoneme (/p/) & -17.48704 & 3.67678 & -4.756 \\
\hline Phoneme (/t/) & -2.62778 & 3.58413 & -0.733 \\
\hline Language (French) & -21.19014 & 4.73436 & -4.476 \\
\hline Inhibitory skill & 20.99973 & 6.57067 & 3.196 \\
\hline Length of residence & -0.07058 & 0.08833 & -0.799 \\
\hline Phoneme $/ \mathrm{p} / \times$ language (French) & -4.31626 & 6.69327 & -0.645 \\
\hline Phoneme $/ \mathrm{t} / \times$ Language (French) & -5.43111 & 6.69373 & -0.811 \\
\hline Inhibitory skill $\times$ length of residence & 1.75285 & 0.43644 & 4.016 \\
\hline Language $($ French) $\times$ inhibitory skill & -17.31202 & 3.42089 & -5.061 \\
\hline Language $($ French $) \times$ length of residence & -0.14672 & 0.04599 & -3.191 \\
\hline Language (French) $\times$ inhibitory skill $\times$ length of residence & -1.05514 & 0.22729 & -4.642 \\
\hline
\end{tabular}

Table of results for the analysis of VOTs in English:

\begin{tabular}{lrrr}
\hline Variable & Estimate $(\boldsymbol{\beta})$ & SD & \multicolumn{1}{c}{$\boldsymbol{t}$} \\
\hline (Intercept) & 70.14476 & 3.23927 & 21.654 \\
Phoneme (/p/) & -17.48704 & 3.57264 & -4.895 \\
Phoneme (/t/) & -2.62778 & 3.57264 & -0.736 \\
Inhibitory skill & 20.77060 & 10.24971 & 2.026 \\
Length of residence & -0.08263 & 0.13779 & -0.600 \\
Inhibitory skill $\times$ length of residence & 1.63201 & 0.68081 & 2.397 \\
\hline
\end{tabular}

Table of results for the analysis of VOTs in French:

\begin{tabular}{lrrr}
\hline Variable & Estimate $(\boldsymbol{\beta})$ & SD & \multicolumn{1}{c}{$\boldsymbol{t}$} \\
\hline (Intercept) & 48.90903 & 3.77299 & 12.963 \\
Phoneme (/p/) & -21.78362 & 4.99634 & -4.360 \\
Phoneme (/t/) & -2.62778 & 4.89303 & -1.647 \\
Inhibitory skill & 2.76778 & 7.21331 & 0.384 \\
Length of residence & -0.20561 & 0.09698 & -2.120 \\
Inhibitory skill $\times$ length of residence & 0.49407 & 0.47912 & 1.031 \\
\hline
\end{tabular}

Table of results for VOTs in the free conversation:

\begin{tabular}{lrrr}
\hline Variable & Estimate $(\boldsymbol{\beta})$ & SD & \multicolumn{1}{c}{$\boldsymbol{t}$} \\
\hline (Intercept) & 60.4741 & 2.1824 & 27.710 \\
Phoneme (/p/) & -10.8678 & 2.1078 & -5.156 \\
Phoneme (/t/) & 2.6452 & 2.1169 & 1.250 \\
Inhibitory skill & 22.6940 & 9.0086 & 2.519 \\
Length of residence & -0.1251 & 0.1189 & -1.052 \\
Inhibitory skill $\times$ length of residence & 1.3915 & 0.5902 & 2.358 \\
\hline
\end{tabular}

\section{Appendix C. Tables of results of Experiment 2}

Table of results for the phoneme categorization task in Experiment 2:

\begin{tabular}{lcrrr}
\hline Variable & Estimate $(\boldsymbol{\beta})$ & SD & $\boldsymbol{z}$ & $\boldsymbol{p}$ \\
\hline Intercept) & 17.864647 & 1.452828 & 12.296 & $<2 \mathrm{e}-16$ \\
Item & -1.552338 & 0.121889 & -12.736 & $<2 \mathrm{e}-16$
\end{tabular}




\begin{tabular}{|c|c|c|c|c|}
\hline Hand & -5.115105 & 2.166111 & -2.361 & 0.01820 \\
\hline Item $\times$ inhibitory skill & -0.830810 & 0.373445 & -2.225 & 0.02610 \\
\hline Inhibitory skill $\times$ length of residence & 0.730437 & 0.277822 & 2.629 & 0.00856 \\
\hline Item $\times$ hand & 0.335489 & 0.183170 & 1.832 & 0.06701 \\
\hline Item $\times$ inhibitory skill $\times$ length of residence & -0.071061 & 0.024831 & -2.862 & 0.00421 \\
\hline
\end{tabular}

Table of results for the analysis of items $8-10$ in the phoneme categorization task in Experiment 2:

\begin{tabular}{|c|c|c|c|c|}
\hline Variable & Estimate $(\beta)$ & SD & $z$ & $p$ \\
\hline (Intercept) & 3.15132 & 0.41395 & 7.613 & $2.68 \mathrm{e}-14$ \\
\hline Hand & -1.87293 & 0.62637 & -2.990 & 0.00279 \\
\hline Length of residence & -0.01122 & 0.01923 & -0.584 & 0.55942 \\
\hline Inhibitory skill $\times$ length of residence & 0.02844 & 0.08217 & 0.346 & 0.72930 \\
\hline
\end{tabular}

Table of results for the analysis of items $11-15$ in the phoneme categorization task in Experiment 2:

\begin{tabular}{|c|c|c|c|c|}
\hline Variable & Estimate $(\beta)$ & SD & $z$ & $p$ \\
\hline (Intercept) & -1.036389 & 0.293696 & -3.529 & 0.000417 \\
\hline Hand & -0.664654 & 0.492704 & -1.349 & 0.177340 \\
\hline Inhibitory skill & 0.126813 & 1.019485 & 0.124 & 0.901007 \\
\hline Length of residence & -0.003878 & 0.019261 & -0.201 & 0.840432 \\
\hline Inhibitory skill $\times$ length of residence & -0.072825 & 0.085504 & -0.852 & 0.394377 \\
\hline
\end{tabular}

\section{References}

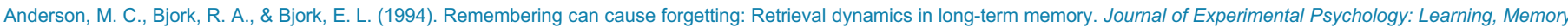
and Cognition, 20(5), 1063-1087.

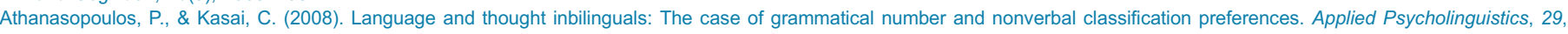
105-123.

Baayen, R. H. (2008). Analyzing linguistic data. A practical introduction to statistics using R. Cambridge, UK: Cambridge University Press.

Bialystok, E., \& Craik, F. I. M. (2010). Cognitive and linguistic processing in the bilingual mind. Current Directions in Psychological Science, 19, 19-23.

Chang, C. B. (2012). Rapid and multifaceted effects of second-language learning on first-language speech production. Journal of Phonetics, 40(2), $249-268$.

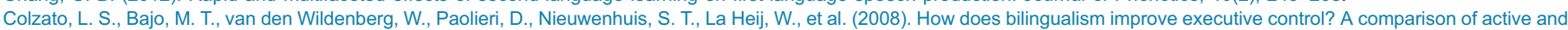
reactive inhibition mechanisms. Journal of Experimental Psychology: Learning, Memory, and Cognition, 34, 302-312.

Cook, V. (Ed.). (2003). Effects of the second language on the first. Clevedon: Multilingual Matters.

Costa, A., Hernández, M., \& Sebastián-Gallés, N. (2008). Bilingualism aids conflict resolution: Evidence from the ANT task. Cognition, $106,59-86$.

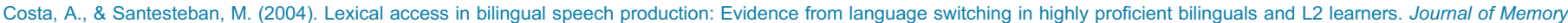
and Language, 50, 491-511.

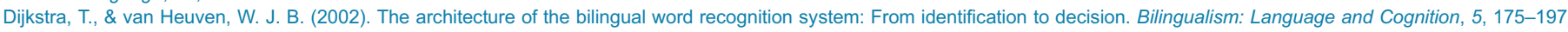

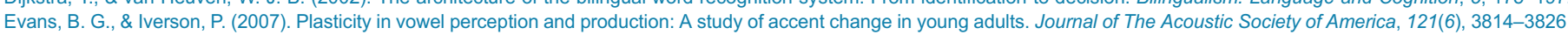

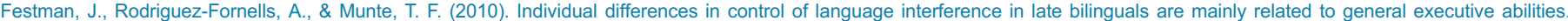
Behavioral and Brain Functions, 6, 5

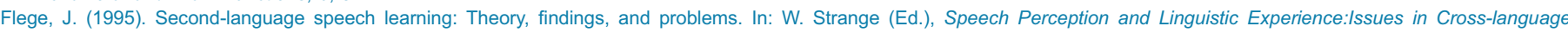
Research (pp. 229-273). Timonium, MD: York Press.

Flege, J. (1987). The production of "new" and "similar" phones in a foreign language: evidence for the effect of equivalence classification. Journal of Phonetics, 15, 47-65.

Flege, J., Bohn, O.-S., \& Jang, S. (1997). The effect of experience on nonnative subjects' production and perception of English vowels. Journal of Phonetics, 25, 437-470.

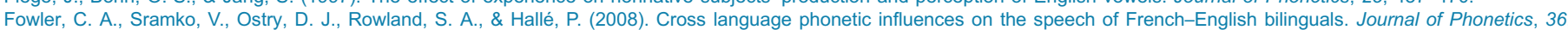
649-663.

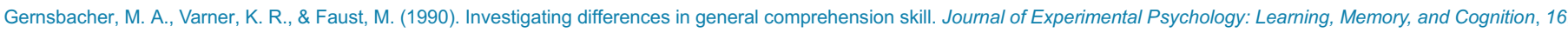
$430-445$

Giora, R. (2003). On our mind: salience, context, and figurative language. New York: Oxford University Press.

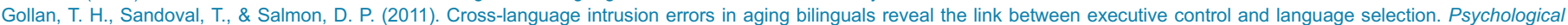
Science, 22(9), 1155-1164.

Green, C. S., \& Bavelier, D. (2003). Action video game modifies visual selective attention. Nature, 423, 534-537.

Green, D. W. (1998). Mental control of the bilingual lexicosemantic system. Bilingualism: Language and Cognition, 1,67-81.

Hoshino, N., \& Kroll, J. F. (2008). Cognate effects in picture naming: Does cross-language activation survive a change of script?. Cognition, 106, 501-511.

Jaeger, T. F. (2008). Categorical data analysis: Away from ANOVAs (transformation or not) and towards Logit Mixed Models. Journal of Memory and Language, 59, 443-446.

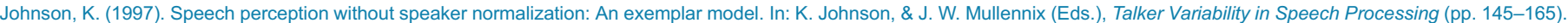
San Diego: Academic Press.

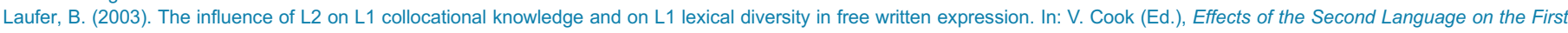
(pp. 19-31). Clevedon, UK: Multilingual Matters.

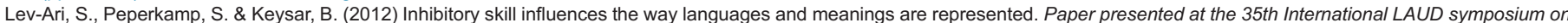
Cognitive Psycholinguistics, University of Koblenz-Landau, Germany. 


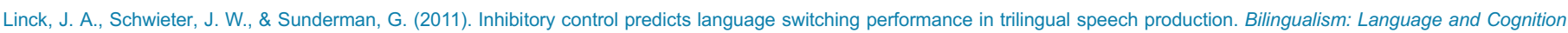
15(3), 651-662.

Lisker, L., \& Abramson, A. S. (1964). A cross-language study of voicing in initial stops: Acoustical measurements. Word, $20,384-422$.

Major, R. C. (1992). Losing English as a first language. The Modern Language Journal, 76, 190-208.

Meuter, R. F. I., \& Allport, A. (1999). Bilingual language switching in naming: Asymmetrical costs of language selection. Journal of Memory and Language, 40, 25-40.

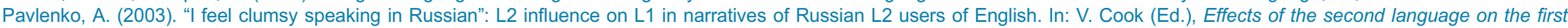
(pp. 32-61). Clevedon UK: Multilingual Matters.

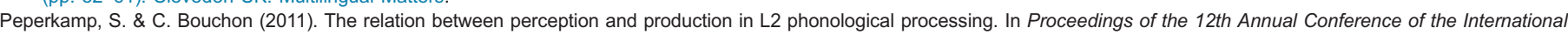
Speech Communication Association (Interspeech 2011) (pp. 161-164). Rundle Mall: Causal Productions.

Sancier, M. L., \& Fowler, C. A. (1997). Gestural drift in a bilingual speaker of Brazilian Portuguese and English. Journal of Phonetics, $25,421-436$.

Spivey, M. J., \& Marian, V. (1999). Cross talk between native and second languages: Partial activation of an irrelevant lexicon. Psychological Science, 10(3), $281-284$.

Sumner, M., \& Samuel, A. G. (2009). The role of experience in the processing of cross-dialectal variation. Journal of Memory and Language, 60, 487-501.

Treccani, B., Argyri, E., Sorace, A., \& Della Sala, S. (2009). Spatial negative priming in bilingualism. Psychonomic Bulletin and Review, $16(2), 320-327$.

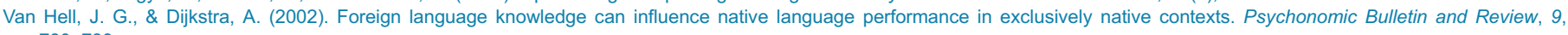
780-789.

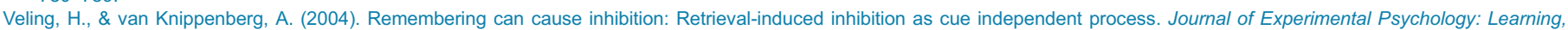
Memory, and Cognition, 30, 315-318.

Wu, Y. J., \& Thierry, G. (2010). Chinese-English bilinguals reading English hear Chinese. Journal of Neuroscience, 30, $7646-7651$. 